\title{
ANALISE DA CONCEPÇÃO E DAS HABILIDADES DOS \\ PROFESSORES DO ENSINO MÉDIO SOBRE A PRÁTICA \\ INTERDISCIPLINAR NO COLÉGIO ESTADUAL DEPUTADO \\ JAYRO SENTO-SÉ
}

\author{
Helisandra dos Reis Santos
}

RESUMO: Este artigo apresenta a análise de um estudo sobre a prática interdisciplinar dos professores do Colégio Estadual Dep. Jayro Sento-Sé, com o objetivo de analisar a concepção e as habilidades dos professores do ensino médio sobre prática interdisciplinar no Colégio Estadual Deputado Jayro Sento-Sé, na cidade de Sento-Sé/Bahia no ano de 2017. A pesquisa é de enfoque qualitativo e quantitativo, com desenho não experimental, com corte transversal, do tipo descritiva que buscou, inicialmente, elaborar uma revisão da literatura referente a temática, em seguida aplicação de questionário e observação participante durante os momentos de atividade complementar e reuniões pedagógicas e análise do Projeto Político Pedagógico com o objetivo de colher informações necessárias à realização da pesquisa em apresentação. No entanto, o resultado desta pesquisa nos possibilitou perceber que os professores reconhecem a importância da prática interdisciplinar para a promoção da aprendizagem significativa, apontaram os fatores que podem dificultar o desenvolvimento da interdisciplinaridade na Unidade Escolar.

Palavras-chave: interdisciplinaridade, contextualização, prática docente e integração.

RESUMEN: Este artículo presenta el análisis de un estudio sobre la práctica interdisciplinaria de los profesores del Colegio Estadual Deputado Jayro Sento-Sé, con el objetivo de analizar la concepción y las habilidades de los profesores de la enseñanza media sobre práctica interdisciplinaria en el Colegio Estadual Diputado Jayro Sento-Sé en la ciudad de Sento-Sé / Bahía en el año 2017. La investigación es de enfoque cualitativo y cuantitativo, con diseño no experimental, con corte transversal, del tipo descriptivo que buscó, inicialmente, elaborar una revisión de la literatura referente a la temática, en a continuación aplicación de cuestionario y observación participante durante los momentos de actividad complementaria y reuniones pedagógicas y análisis del Proyecto Político Pedagógico con el objetivo de recoger informaciones necesarias para la realización de la investigación en presentación. Sin embargo, el resultado de esta investigación nos posibilitó percibir que los profesores reconocen la importancia de la práctica interdisciplinaria para la promoción del aprendizaje significativo, apuntar los 
factores que pueden dificultar el desarrollo de la interdisciplinariedad en la Unidad Escolar.

Palabras clave: interdisciplinariedad, contextualización, práctica docente e integración.

\section{INTRODUÇÃO}

As discussões sobre a prática interdisciplinar vêm assumindo importância e ocupando cada vez mais espaço no campo das pesquisas em educação, principalmente com enfoque metodológico e pedagógico de grande relevância para a superação da fragmentação do conhecimento. Do ponto de vista epistemológico a interdisciplinaridade apresenta alta complexidade, pois é uma condição necessária para o estudo de fenômenos sociais, econômicos, culturais e científicos.

A interdisciplinaridade traz a possibilidade de desenvolver uma metodologia que busca o compartilhamento do conhecimento com uma visão holística do todo, mesmo através de diferentes disciplinas que se encontram estruturadas no currículo de maneira hierarquizada pelo sistema escolar. A integração dos professores e a interação na comunicação entre as disciplinas têm fundamental importância para o desenvolvimento dessa prática metodológica.

A estrutura curricular hierarquizada no sistema escolar e a formação dos professores fragmentada, muitas vezes acabam tornando difícil o exercício da prática interdisciplinar. Assim, precisamos dar importância ao desenvolvimento dessa prática no currículo escolar, para promover a contextualização do ensino, levando em consideração as diversidades sociais, econômicas e culturais, como perspectiva de transformação social.

A interdisciplinaridade exige a interação na comunicação entre as disciplinas das diversas áreas do saber, para construir o conhecimento com uma visão holística do todo. Para tais mudanças, é necessário promover no ambiente educacional a integração curricular, num processo interdisciplinar, contextualizando os conteúdos com a realidade vivida, buscando formar cidadãos autônomos e críticos que possam interagir e intervir no meio social em que estão inseridos, na perspectiva da formação humana integral. 


\section{INTERDISCIPLINARIDADE: UM OLHAR NA HISTÓRIA}

A abordagem da prática interdisciplinar é bem antiga, vem desde a antiguidade das sociedades grega e romana. Gusdsorf (1995) relata que na época medieval, manifestou-se através da divisão do conhecimento em dois grandes segmentos: o trivium (gramática, retórica e dialética) e o quadrivium (aritmética, geometria, astronomia e música) que dominou toda época, seriam a mesma base da educação da modernidade. No início da era da modernidade com a proliferação da especialização dos saberes surgiu à fragmentação do conhecimento, que ainda caracteriza os currículos escolares da sociedade contemporânea. Mas, a partir do final do século XX essa especialização começa a ser descaracterizada, a ideia de totalidade passa a ser discutida pelos estudiosos defendendo uma visão menos fragmentada da realidade.

Na década de 60 a interdisciplinaridade torna-se mais abrangente, a aproximação dos conhecimentos teóricos e a aplicação na prática começa a ser desenvolvida. Jantsch (1995, p. 35) relata que "os estudantes queriam que seus estudos tivessem uma 'utilidade', pretendendo assim que estabelecessem um vínculo bem visível entre a ciência e a sociedade". Os movimentos estudantis de 1968, na França, fizeram com que o princípio da interdisciplinaridade fosse incorporado à educação, como proposta de integração, devido à intensa fragmentação disciplinar que caracterizava os currículos de escolas e universidades. Fazenda (1994, p. 18) conta que, "os movimento da interdisciplinaridade surge na Europa, principalmente na França e na Itália, em meados da década de 1960 [...], época em que surgem os movimentos estudantis, reivindicando um novo estatuto de universidades e escolas".

A interdisciplinaridade surge como resposta às reivindicações de um ensino em sintonia com a prática e teoria, relacionando os conteúdos estudados com as questões sociais, políticas e econômicas da época. A título de ilustração, os estudiosos ao compreenderem os problemas referentes ao crescimento populacional, não poderiam pensar em resolvê-los somente tomando como referência um único campo do conhecimento, interessavam-se por tudo, até à poluição da atmosfera e as alterações climáticas uma vez que existem as interfaces entre os objetos em pauta. 
No Brasil, o conceito de interdisciplinaridade chegou com a obra de Georges Gusdorf, (professor e pensador francês) seguida pela obra do epistemólogo Jean Piaget. O primeiro influenciou o pensamento de Hilton Japiassu na epistemologia e o de Ivani Catarina Arantes Fazenda na educação. Chegando ao Brasil no final da década de 1960, conforme se ler:

[...] o eco das discussões sobre interdisciplinaridade chega ao Brasil ao final da década de 1960 com sérias distorções, próprias daqueles que se aventuram ao novo sem reflexão, ao modismo sem medir as consequências do mesmo[...]. o modismo que o vocábulo desencadeou, passou a ser palavra de ordem empreendida na educação, aprioristicamente, sem atentar para os princípios, muito menos para as dificuldades de sua realização. (FAZENDA, 1994, p.23).

Carlos (2007) atribui à compreensão rápida e superficial da interdisciplinaridade no sistema educacional brasileiro resultado do modismo que perpetua até os dias atuais, devido à precocidade assimilada ao sistema sem uma reflexão, discussão e adequação às peculiaridades de nosso sistema de ensino. É um termo que aparece frequentemente na fala dos professores em momentos de elaboração de projeto pedagógico e plano de curso. Entretanto, ao desenvolver iniciativas interdisciplinares se deparam com dificuldades que desafiam e acabam desestimulando os professores, devido ao pouco conhecimento da didática interdisciplinar.

A ideia de interdisciplinaridade chegou ao Brasil em um momento de instabilidade social e política, no meio da ditadura militar. Época em que a Lei de Diretrizes e Bases da Educação Nacional (LDBEN) Lei nº5.672/71 estava em processo de formulação e acabou sofrendo algumas influências desses novos ideais.

Segundo Fazenda (1994, p.17) em uma retrospectiva histórica das discussões dos educadores que estudam e pesquisam a inserção da interdisciplinaridade como princípio pedagógico nas escolas e universidades, divide as três últimas décadas do século XX em três fases.

A primeira fase começa na década de 70, buscava-se a construção epistemológica e a definição da interdisciplinaridade. A segunda caracterizou-se pela explicitação das 
contradições epistemológicas e a tentativa de desenvolver um método interdisciplinar, isso na década de 80. A última fase em 90 buscou-se uma nova epistemologia, uma teoria sobre interdisciplinaridade e os educadores reconheciam a interdisciplinaridade como uma exigência na proposta educacional para o desenvolvimento do conhecimento.

No século XXI a interdisciplinaridade é retomada na educação como uma proposta pedagógica capaz de atender o desafio de educar as novas gerações no mundo globalizado, ameaçado pela diversidade social, econômica, política e cultural.

Apesar de aparecer um modismo à interdisciplinaridade ganhou força no meio educacional como um dos princípios norteadores de ações pedagógicas, presentes em documentos oficiais do Ministério da Educação, como os Parâmetros Curriculares Nacionais (PCNs), Diretrizes Curriculares Nacionais do Ensino Médio (DCNEM), que complementam a legislação educacional, a Lei de Diretrizes e Bases da Educação Nacional (LDBEN) de $n^{\circ}$ 9.394/96.

\section{A NECESSIDADE DE UMA PRÁTICA INTERDISCIPLINAR}

\subsection{O sentido da prática interdisciplinar}

$\mathrm{Na}$ atualidade um dos grandes problemas que os professores se deparam em sala de aula é a falta interesse dos estudantes. Raramente os alunos conseguem articular o conhecimento que aprende em cada disciplina, devido ao ensino de maneira compartimentada, como se cada conhecimento fosse armazenado em uma gaveta ou arquivo. A desarticulação entre as áreas do saber ainda é uma realidade da educação contemporânea, que dificulta o processo de ensino, gerando a desmotivação no ambiente escolar.

Mas desde 1989, Fazenda já observa essa falta de interesse e de comunicação entre professor e aluno, verificando que era algo que precisava ser trabalho em sala de aula, para melhorar essa postura.

Somos produtos da "escola do silêncio", em que um grande número de alunos apaticamente fica sentado diante do professor, esperando receber dele todo o conhecimento. Classes numerosas, conteúdos extensos, completam o quadro desta que se cala. Isso complica muito quando já se é introvertido (Fazenda, 1989, p.15). 
A interdisciplinaridade é uma das ferramentas que traz a possibilidade de promover a motivação, o entusiasmo e interesse dos estudantes. Através de sua proposta metodológica, é possível envolvê-los, dando sentido aos conteúdos que são estudados em dimensão social, política, ambiental e econômica, relacionando-os com o contexto da realidade local, regional e global, para promover uma melhor compreensão e transformação da realidade. Conforme Fazenda (2011, p.84) "o valor e a aplicabilidade da interdisciplinaridade, portanto, podem-se verificar tanto na formação geral, profissional, de pesquisadores, quanto como meio de superar a dicotomia ensino-pesquisa e como forma de permitir uma educação permanente".

Para Morin (2006, p.22), “a educação deveria mostrar as correlações entre os saberes, a complexidade da vida e dos problemas que hoje existem. Caso contrário, será sempre ineficiente e insuficiente para o cidadão do futuro. A reforma mais ampla no ensino pode começar a ser feita em cada sala de aula".

Como educadores precisamos acreditar em mudanças de hábitos, no âmbito de nossa prática docente, para tentar abrir espaços que possibilitem a reconstrução da sociedade. Carecemos buscar no desenvolvimento de uma ética de responsabilidade social, ações que visem o bem coletivo. Sensibilizando no nosso cotidiano a construção de uma consciência cidadã. . De acordo com Fazenda (2003, p.31) “o professor interdisciplinar traz em si um gosto especial por conhecer e pesquisar possui um grau de comportamento diferenciado para com seus alunos, ousa novas técnicas e procedimentos".

A prática interdisciplinar nos traz a possibilidade de fortalecer o trabalho coletivo. A metodologia interdisciplinar vai a além da integração das disciplinas, busca a interação dos profissionais da educação, desenvolvendo um trabalho através do diálogo, da parceria, da reconstrução do conhecimento.

Hartmann (2007) confirma que:

A metodologia interdisciplinar pressupõe uma comunicação entre conhecimento e sujeitos. A comunicação, por sua vez, pressupõe uma linguagem comum que só será compreendida quando os interessados conhecerem seus símbolos e códigos. No trabalho escolar, o domínio da linguagem de cada disciplina é uma competência que os estudantes precisam desenvolver. Mas esse domínio não se faz, necessariamente, de 
forma isolada pelas disciplinas. Quando existe uma articulação entre elas, a leitura e a interpretação destas linguagens é promovida por todas integralmente, algo que pode parecer bastante difícil a princípio, mas que é possível quando existe uma atitude interdisciplinar por parte dos sujeitos. (p.55).

A interdisciplinaridade pode ser utilizada como um instrumento de transformação de social, em que o sujeito se reconhece como construtor de sua própria história e do conhecimento, intervindo e interagindo no meio social no qual está inserido. Passando a reconhecer que os conteúdos estudados em sala de aula estão relacionados com o cotidiano.

\subsection{Contextualização e interdisciplinaridade na educação}

A sociedade contemporânea vive a era da informação. Os avanços tecnológicos, e as políticas econômicas, forçando novas formas de ser e estar em sociedade e acabam interferindo na prática docente. As novas tendências da sociedade influenciam os sistemas educacionais. Por isso, fala-se tanto em contextualização e interdisciplinaridade que é a consciência da necessidade de um inter-relacionamento explícito e direto entre as disciplinas e fazer do aluno um ser protagonista, trazendo o cotidiano para a sala de aula e aproximando o dia a dia dos alunos ao conhecimento científico.

A escola tem a necessidade de promover no ambiente educacional a integração curricular, desenvolvendo a interdisciplinaridade e a contextualização dos conteúdos com a sua realidade, na perspectiva da formação humana integral, buscando formar cidadãos autônomos e críticos.

A experiência concreta da vida dos alunos não fica do lado de fora da escola. Conectar os conteúdos escolares ao interesse dos jovens estudantes pressupõe entende-los como produtores de discursos, em que selecionam, categorizam e organizam, a partir de suas experiências, todos os enunciados que lhes são dirigidos (Fígaro, 2010, p.27).

De acordo com Carlos (2007, pp. 15-16),

[...]a interdisciplinaridade para a vida pode ser vista como uma nova maneira de conceber o mundo em sua multiplicidade e de propiciar ao 
aluno uma formação mais consciente e completa que lhe garanta as prerrogativas de um cidadão atuante num mundo globalizado marcado pela complexidade das interações sócio-ambientais e econômicas.

Hartmann (2007, p.18) menciona que essa forma de entender e organizar o currículo envolve os dois conceitos que estão intensamente interligados: a interdisciplinaridade e a contextualização. A interdisciplinaridade é uma condição necessária para o estudo de fenômenos sociais, econômicos, culturais e científicos [...], a contextualização é um recurso para estudo desses fenômenos.

A educação da contemporaneidade busca a construção do conhecimento pertinente para atender as necessidades das demandas sociais. Esse conhecimento pertinente pode ser construído com o auxílio da prática interdisciplinar. Conforme Morin (2016, p.40), “para que um conhecimento seja pertinente, a educação deverá então tornar evidente: o contexto, o global, o multidimensional, o complexo".

Precisamos entender o currículo como campo político-pedagógico, no qual várias relações entre os sujeitos, conhecimento e realidade que constroem e reconstroem os novos saberes. Currículo e Contextualização são dois elementos que estão associados. Neste processo dinâmico de diálogo, a realidade é o alicerce sobre o qual o educador e educando devem construir metodologias de ensino e aprendizagem. A realidade não é um elemento que está fora da prática educativa, é uma ferramenta para despertar a aprendizagem significativa. Santos $(2007$, p.40) menciona que: "a cultura local, até então ignorada e desprezada pela escola, a partir dessa nova perspectiva construirá fator importante na organização curricular, tendo em vista o processo de busca permanente pelo conhecimento".

A Base Nacional Comum Curricular (BNCC) é um documento que apresenta os direitos e objetivos da aprendizagem e desenvolvimento que visa orientar a construção do currículo para as diferentes etapas da educação brasileira, em conformidade com o Plano Nacional de Educação (PNE) e a Conferência Nacional de Educação (CONAE). Esse documento tem papel de assegurar as aprendizagens essenciais definidas em cada etapa da educação básica, considerando o contexto e as características do aluno, o BNCC (2017, p.12) traz como ação:

- contextualizar os conteúdos dos componentes curriculares, identificando estratégias para apresentá-los, representá-los, exemplificá-los, conectá-los 
e torná-los significativos, com base na realidade do lugar e do tempo nos quais as aprendizagens estão situadas;

- decidir sobre formas de organização interdisciplinar dos componentes curriculares e fortalecer a competência pedagógica das equipes escolares para adotar estratégias mais dinâmicas, interativas e colaborativas em relação à gestão do ensino e da aprendizagem;

A intenção e a forma como os elementos se inter-relacionam, visualiza o ser humano por completo, dando possibilidade e flexibilidade de compreender as demandas, as necessidades e dificuldades de uma sociedade. Podendo formar cidadãos mais preparados para conviver em sociedade, voltado para o desenvolvimento pessoal, levando em consideração os fatores psicológicos, sociais para a efetivação da aprendizagem, pois, a educação não é desinteressada e nem neutra.

A construção do currículo deve estar em consonância com os sujeitos e o entorno da comunidade escolar para os quais ele destina-se, e em conformidade com as transformações históricas e sociais. A partir da contextualização dos fenômenos naturais e culturais, de sua significação com relação às experiências dos sujeitos, bem como a necessidade de superação das desigualdades humanas e tecnológicas, da ausência de hierarquia entre os saberes, as áreas e as disciplina.

\subsection{Uma ação comunicativa}

A comunicação é de extrema importância para o convívio em sociedade, e no processo educativo não é diferente. A ação comunicativa é um elemento presente na prática pedagógica. Para Habermas, filósofo e sociólogo alemão define a Teoria da Ação Comunicativa como uma teoria crítica e reflexiva, onde a teoria de entrelaça com a prática para promover a liberdade entre os sujeitos, usando a comunicação para chega a um entendimento. Conforme suas palavras:

Chamo ação comunicativa (grifos do autor) àquela forma de interação social em que os planos de ação dos diversos atores ficam coordenados pelo intercâmbio de atos comunicativos, fazendo, para isso, uma utilização da linguagem (ou das correspondentes manifestações extraverbais) orientada ao entendimento. À medida que, a comunicação serve ao entendimento (e não só ao exercício das influências recíprocas) pode 
adotar para as interações o papel de um mecanismo de coordenação da ação e com isso fazer possível a ação comunicativa. (Habermas, 1997, p.418).

Nessa perspectiva a prática interdisciplinar é uma ação comunicativa, pois exige a comunicação entre os professores, alunos e conteúdos, no contexto histórico, cultural, econômico, político, dentre outros. A partir dessa integração e do diálogo o conhecimento produzido terá significado.

Para que a prática interdisciplinar se efetive é necessária a interação de dois ou mais professores, que possam desenvolver estratégias e colocar em prática o ensino através da interdisciplinaridade, construindo uma relação de diálogo entre professorprofessor e professor-aluno. Conforme Fazenda (2011, p.11) “a importância metodológica é indiscutível, porém é necessário não fazer dela um fim, pois interdisciplinaridade não se ensina nem se aprende, apenas vive-se, exerce-se e, por isso, exige uma nova pedagogia, a da comunicação”. O Professor é o mediador na construção do conhecimento, direcionando o caminho, mostrando como e onde encontrar a informação. Paviani $(2014$, p.56) afirma que "o professor é o especialista que ensina o aluno como acessar as informações, como ir às fontes, como delimitar e formular problemas, como aplicar os resultados dos conhecimentos".

Partindo do princípio que a educação é um processo contínuo, e dinâmico formador na construção e reconstrução do sujeito, e que o desenvolvimento da prática interdisciplinar exige um vínculo de interação entre a comunidade escolar. De acordo com Paviani (2014, p.16):

[...] não é demais reforçar a ideia de que a interdisciplinaridade realiza-se em cada situação de modo peculiar e pressupõe integração de conhecimento e de pessoas, de unidades e de sínteses de conhecimento ou de "conteúdo", do uso ou da aplicação de teorias e métodos e de colaboração (princípio da colaboração) entre professores ou pesquisadores.

$\mathrm{Na}$ interdisciplinaridade o conhecimento se dá por meio da comunicação através da competência do diálogo. Fazenda (2003) defende que a prática interdisciplinar é um trabalho em colaboração que permite a formação de parcerias de trabalho entre os sujeitos 
que promovem a ação. Essa parceria se estabelece através do diálogo na busca de novos conhecimentos, onde os pensamentos entre os sujeitos envolvidos no processo possam se complementar.

O que nosso trabalho tem revelado é que, quer queiramos ou não, nós educadores sempre somos parceiros; parceiros dos teóricos que lermos, parceiros de outros educadores que lutam por uma educação melhor, parceiros de nossos alunos, na tentativa da construção de um conhecimento mais elaborado. (Fazenda, 2012, p.85).

Portanto, a organização da ação interdisciplinar necessita da articulação, do diálogo, da integração, da interação, do entendimento entre as partes envolvidas. Nessa perspectiva, o desenvolvimento da prática interdisciplinar está vinculado à ação comunicativa dos sujeitos envolvidos no processo educativo. É através dessa educação dialógica que os homens podem alcançar a liberdade de pensamento e buscar a transformação do mundo.

\section{INTERDISCIPLINARIDADE NA PRÁTICA PEDAGÓGICA DO PROFESSOR: A FORMAÇÃO REFLEXIVA}

O ensino interdisciplinar exige uma atitude de abertura, de opinião crítica, de diálogo, de reflexão sobre a própria prática. É um ensino que busca a formação integral do cidadão, promovendo a autonomia, o senso crítico e reflexivo, para compreender o contexto social, para intervir no meio em que está inserido. Para interferir na realidade Paviani (2014, p.58) diz que o profissional precisa "buscar conhecimentos de diversas áreas e não apenas numa determinada ciência ou disciplina”. É preciso está aberto para o questionamento, Fazenda (2012, pp.44-45) afirma que,

[...] é fundamental que o professor seja mestre, aquele que sabe aprender com os mais novos, porque mais criativos, mais inovadores, porém não com a sabedoria que nos anos de vida vividos outorgam um mestre. Conduzir sim, eis a tarefa de ser mestre. O professor precisa ser condutor do processo, mas é necessário adquirir a sabedoria da espera, o saber ver no aluno aquilo que nem o próprio aluno havia lido nele mesmo, ou em suas produções. 
A característica da reflexão é uma das tendências dominantes na formação de professores. O ensino acontece através da relação entre sujeitos (professor-aluno) e conhecimento, e a prática reflexiva na profissão docente é uma condição necessária para analisar, criticar, modificar e promover o trabalho coletivo no ambiente escolar. Shön (2000, p.23) aponta que os profissionais "terão que aprender sobre suas teorias tácitas, os professores das disciplinas sobre os métodos de investigação; os instrutores sobre as teorias e os processos que eles trazem em sua própria reflexão na ação”.

Em consonância com o fazer pedagógico reflexivo Freire (1996, p.43) vem mencionar que: "a prática docente crítica, implicante do pensar certo, envolve o movimento dinâmico, dialético, entre o fazer e o pensar sobre o fazer. [...] É pensando criticamente a prática de hoje ou de ontem que se pode melhorar a próxima prática".

$\mathrm{Na}$ formação inicial o futuro professor necessita apropriar-se de conhecimentos e exercê-los na prática, para desenvolver habilidades do professor reflexivo, que reflete criticamente sobre sua prática pedagógica. A prática do professor precisa está em constante construção, pois nas salas de aulas existem várias dimensões a serem trabalhadas. De acordo com Perrenoud (2002, p.30), "a prática reflexiva pode ser entendida, no sentido mais comum da palavra, como a reflexão acerca da situação, dos objetivos, dos meios, do lugar, das operações envolvidas, dos resultados provisórios, da evolução previsível do sistema da ação".

Na defesa da formação docente teórico-prática, Borges (2008, p.22) salienta que:

Tornar-se professor é um processo de desenvolvimento profissional que se constrói gradualmente em uma trajetória de vida pessoal e profissional. Assim considerada, a formação não pode ser tratada como elemento totalizador, mas integrador deste processo formativo que se faz na relação teoria e prática.

Sabemos que a maior parte dos professores que estão atuando na educação básica brasileira, são profissionais que vêm de uma formação inicial realizada de maneira fragmenta e descontextualizada. Com 3 (três) anos iniciais estudando a teoria e 1 (um) ano final desenvolvendo a prática. Professores que terminam sua formação inicial sem está preparado para enfrentar a realidade vivenciada em sala de aula, os conhecimentos teóricos confrontados com a prática cotidiana são insuficientes e inúteis. Esse é um 
conflito marcado pela ausência do diálogo entre a teoria e prática que necessitam andar em parceria e acaba dificultando a formação docente

Mas precisamos superar essa dicotomia entre o fazer e o pensar, e assumirmos uma postura de professor reflexivo, mesmo diante das dificuldades. Para Masetto (2000, p.142)

Para nós, professores, essa mudança de atitude não é fácil. Estamos acostumados e sentimo-nos seguros com o nosso papel de comunicar e transmitir algo que conhecemos muito bem. Sair dessa posição, entrar em diálogo direto com os alunos, correr risco de ouvir uma pergunta para a qual no momento talvez não tenhamos resposta, e propor aos alunos que pesquisemos juntos para buscarmos resposta - tudo isso gera um grande desconforto e uma grande insegurança.

Nesse sentido, podemos visualizar a prática pedagógica como interdisciplinar, e a reflexão crítica do professor em sala de aula faz parte dessa metodologia de construção do conhecimento, onde professor e alunos são parceiros nesse processo. Como afirma Fazenda (2002b, p.83), “a obrigação é alternada pela satisfação, a arrogância pela humildade, a solidão pela cooperação, a especialização pela generalidade, o grupo homogêneo pelo heterogêneo, a reprodução pelo questionamento do conhecimento".

Portanto, a formação inicial do professor necessita ser revista pelas universidades e instituições de ensino superior, para formar profissionais que atendam às demandas da realidade no cotidiano escolar. A superação da fragmentação do saber, a contextualização do conhecimento, a aproximação entre a teoria e prática, o pensamento reflexivo e crítico sobre a prática pedagógica, o diálogo e trabalho coletivo, ser mediador na construção do conhecimento, são pontos que precisam ser trabalhos durante os cursos de formação inicial e continuada, para que haja preparação no desenvolvimento da prática interdisciplinar. 


\section{ASPECTOS METODOLÓGICOS}

A presente pesquisa foi realizada no Município de Sento-Sé, situado no território do Sertão do São Francisco, na borda do Lago de Sobradinho, no Norte do Estado da Bahia, no Colégio Estadual Dep. Jayro Sento-Sé, no ano de 2017. A escola atende turmas do Ensino Fundamental II, Ensino Médio e Educação de Jovens e Adultos, nos turnos matutino, vespertino e noturno, com uma população de 701 alunos matriculados e 45 funcionários, sendo 29 professores, a maioria com formação específica e especialização na área de atuação. Sendo a pesquisa realizada com a população de 26 professores do Ensino Médio, mas 2 optaram por não participar.

Diante das perspectivas mencionadas, essa pesquisa visa responder a seguinte pergunta: Qual a concepção e as habilidades dos professores do Ensino Médio sobre a prática interdisciplinar no Colégio Estadual Deputado Jayro Sento-Sé?

É uma pesquisa de natureza qualitativa e quantitativa. Quanto ao qualitativo está relacionado em compreender e interpretar os dados de opiniões dos professores pesquisados, sobre o conhecimento de interdisciplinaridade e refletindo suas concepções e desenvolvimento na prática docente. A quantitativa estará mensurando dados em números e gráficos com as técnicas de estatísticas para averiguar a hipótese em pesquisa e confirmar com exatidão a teoria.

O tipo é descritivo, para Sampieri, Collado e Lucio, (2013, p.102): “Os estudos descritivos buscam especificar as propriedades, as características e os perfis de pessoas, grupos, comunidades, processos, objetos ou qualquer outro fenômeno que se submeta a uma análise".. Com o desenho não experimental, que segundo Sampieri, Collado e Lucio, (2006) é quando realiza a investigação sem manipular deliberadamente as variáveis. de corte transversal. Como técnica para coleta de dados foi utilizado como instrumento de pesquisa o questionário e observação participante, a docentes do Ensino Médio. Iniciouse com uma revisão bibliográfica para a construção do marco teórico desse trabalho, foi utilizado como instrumento de pesquisa o questionário e a observação participante, fazendo levantamento de informações em documentos da escola, com o intuito de refletir sobre a prática pedagógica dos professores base no ensino interdisciplinar. 


\section{PANORAMA E RESULTADOS DA PESQUISA}

Neste capítulo serão expostos e analisados os resultados obtidos durante a investigação, de maneira clara e objetiva, todos gerados a partir dos instrumentos de coleta de dados. Sendo realizada a análise descritiva e inferencial dos dados. Por se tratar de pesquisa mista, este capítulo está subdividido em duas principais seções, os dados qualitativos e os dados quantitativos.

\subsection{Dados qualitativos}

Essa seção vai expor a análise dos qualitativos descritos nesta pesquisa, obtidos por meio da observação participante dos professores.

\subsubsection{Apresentação dos dados da observação participante}

A observação participante foi o instrumento de pesquisa escolhido para entender as atitudes e habilidades dos professores durante o processo de planejamento, chamado de AC (atividade complementar) e reuniões pedagógicas, seguindo um roteiro semiestruturando para registrar as expressões de comportamentos verbais e não verbais, o período da observação aconteceu durante duas semanas.

A observação deu início com a análise da organização pedagógica. A escola não possui coordenador pedagógico, esse é um desafio enfrentado pela gestão da Unidade Escolar (UE) para promover a integração das atividades e interação entre os professores, sendo as reuniões pedagógicas direcionadas pela diretora. Sobre a importância de um coordenador pedagógico para promover a integração do grupo diante dos projetos a serem desenvolvidos.

$\mathrm{Na}$ observação da organização do $\mathrm{AC}$, é realizada semanal e por área do conhecimento. Na terça-feira acontece a da área de Humanas, na quarta-feira a da área de Linguagens e na quinta-feira a da área de Ciências da Natureza e Matemática. Portanto, percebe-se que o planejamento semanal não acontece com o coletivo. Mas as reuniões pedagógicas são realizadas com o coletivo.

Pode-se conhecer a realidade distinta da carga horária dos professores efetivos e contratado. O professor efetivo a cada 20 horas de trabalho, ele trabalha 13 horas em sala de aula e 7 horas são para atividades complementares, sendo 4 horas precisam ser dentro da UE. Já o professor contratado de 20 horas, possui 16 horas aulas em sala de aula e 4 
para atividades complementares, sendo que 2 horas precisam ser na UE. Portanto, podese perceber que nessa distinção da carga horária tanto em sala de aula quanto na atividade complementar na UE o tempo a ser cumprido é diferenciado e tem influência para a comunicação nesses momentos de planejamento semanal que já de certa forma é fragmentado por área do conhecimento.

Os professores que possuem vínculo de contratado com a Secretaria de Educação do Estado da Bahia também possuem vínculo efetivo com a Secretaria de Educação Municipal. Durante as reuniões pedagógicas percebe-se que há a preocupação pela busca de uma organização em relação aos horários para que os todos possam se envolver nas atividades sem comprometer suas atividades das escolas do município. Mesmo com essa organização nota-se que em determinados momentos, como em atividade extraclasse, esses professores precisam optar em qual das escolas iram desenvolver suas atividades. Em algumas situações percebe-se que existem negociações entre a gestão das Unidades Escolares para que nenhuma saia em prejuízo, entrando acordo e dividindo os profissionais quando essas atividades coincidem na mesma data.

Nos momentos de observação participante, também se analisou o PPP da UE, levando em consideração que o mesmo encontrava-se em momento de reestruturação, pode-se constatar que os objetivos específicos mencionam a prática interdisciplinaridade como fator de para o desenvolvimento da aprendizagem dos alunos, traz a elaboração e a implementação de projetos didáticos para a superação de práticas fragmentas.

\subsection{Dados quantitativos}

\subsubsection{Apresentação dos dados do questionário}

O questionário foi aplicado antes da observação participante aos professores do Ensino Médio. Este questionário teve como objetivo principal perceber a concepção e habilidades sobre interdisciplinaridade para diagnosticar o quanto eles conheciam a respeito da prática interdisciplinar.

Através dos questionamentos sobre as concepções da interdisciplinaridade, foi possível perceber que os professores possuem conhecimento sobre as concepções de práticas interdisciplinares.

Ao analisarmos os dados levantados referente ao desenvolvimento da prática docente, pode-se notar que apesar de serem conhecedores da fundamentação teórica da 
prática interdisciplinar não prática a ações que possibilitem o alcance da efetivação da interdisciplinaridade. 


\section{CONSIDERAÇÕES FINAIS}

Vivemos em um mundo globalizado, as informações se cruzam á todo momento e a sociedade contemporânea tem requerido pessoas com visão que ultrapasse o "eu", e compreenda as diversidades e que estabeleça relações com os diversos campos de conhecimentos. Assim se espera que a multiplicidade de saberes contribua para manter diálogos constantes, e possa de fato se instituir um pensamento e uma prática interdisciplinar.

A pesquisa consistiu na prática interdisciplinar como uma pesquisa descritiva, mostrou que é um desafio que pode ser superado. Os professores reconhecem a importância da prática interdisciplinar para a promoção da aprendizagem significativa, apontaram as os fatores que podem dificultar o desenvolvimento da interdisciplinaridade na Unidade Escolar.

Esses resultados demonstram a hipótese como negativa, ou seja, os docentes não estão envolvidos na aplicação do ensino interdisciplinar em sua prática docente no Ensino Médio do Colégio Estadual Deputado Jayro Sento-Sé.

Nesta pesquisa foi possível fazer uma leitura crítica sobre as dificuldades encontradas pelos professores para o desenvolvimento de trabalhos interdisciplinares. E que os estudiosos escrevem sobre as maneiras de desenvolver a prática interdisciplinar no ambiente escolar, mas não existe uma técnica pré-estabelecida para uma prática pedagógica dentro de um modelo interdisciplinar. Citou Peleias et all (2011, p. 506) que, “a definição da interdisciplinaridade parece estar em construção. A demanda por uma definição unívoca e definitiva deve ser a princípio rejeitada, por ser uma proposta construída a partir das culturas disciplinares existentes".

A sociedade contemporânea busca uma educação que possa buscar soluções para os problemas através da interação do conhecimento e das pessoas. Muito se fala e pesquisa sobre a prática interdisciplinar na educação, mas ainda é uma realidade distante dentro da Unidade Escolar que foi pesquisada. Percebe-se que a prática que predomina nesse ambiente educacional é a fragmentação do conhecimento. Mas, nos resultados da pesquisa, foram apontados fatores que podem ser determinantes para que a escola possa buscar alternativas para a implementação da interdisciplinaridade. 
Desse modo, os resultados desta pesquisa colaboram para a compreensão e para a fundamentação da teoria da importância da prática interdisciplinar, colaborando a outros pesquisadores como um potencial exemplo para demais estudos e vivências. 


\section{REFÊNCIAS}

Brasil. (2016). Base Nacional Comum Curricular. PROPOSTA PRELIMINAR. SEGUNDA VERSÃO. REVISTA. Ministério da Educação. Abril.

Borges, L. (2008). Currículo, cultura e docência: uma tríade integrada. In: Galvão, Afonso; Santos, Gilberto Lacerda dos (Orgs.). Escola, currículo e cultura, ensino/aprendizagem, psicologia da educação, trabalho e movimentos sociais. Brasília: Liber Livro; ANPED.

Carlos, J. (2007). Interdisciplinaridade no Ensino Médio: desafios e potencialidades. Tese de mestria, Universidade de Brasília, Brasília, Brasil.

Fazenda, I. C. A. (1994). Interdisciplinaridade: história, teoria e pesquisa. $4^{\mathrm{a}}$ Ed. Campinas: Papirus

(2011). Integração e interdisciplinaridade no ensino brasileiro: efetividade ou ideologia. $6^{\text {a }}$ Ed.São Paulo: Loyola.

(1989). Didática e interdisciplinaridade. Campinas: Papirus.

(2003). Interdisciplinaridade: história, teoria e pesquisa. $11^{\mathrm{a}}$ Ed. Campinas: Papirus.

(2012). Interdisciplinaridade: história, teoria e pesquisa. $18^{\mathrm{a}}$ Ed. Campinas: Papirus.

(2002). Interdisciplinaridade: um projeto em parceria. $5^{\mathrm{a}}$ Ed. São Paulo: Loyola.

Fígaro, R. (2010). Estudos de recepção para entender os usos da mídia na escola. In: Comunicação \& Educação. São Paulo: CCA/ECA/USP, ano XV, n. 3, pp. 17-28

Freire, P. (1996). Pedagogia da Autonomia: saberes necessários à prática educativa. Rio de Janeiro: Paz e Terra, 1996.

Habermas, J. (1997). Teoria de La acción comunicativa: complementos y estúdios prévios.Madrid: Cátedra.

Hartmann, A.(2007). Desafios e possibilidades da interdisciplinaridade no Ensino Médio. Tese de mestria publicada, Universidade de Brasília, Brasília, Brasil.

Jantsch, E.(1995). Interdisciplinaridade: os sonhos e a realidade. Revista Tempo Brasileiro. Rio de Janeiro, $\mathrm{n}^{\mathrm{o}} 121$, pp.29-42, abr.-jun. 
Masetto, M. T. (2000). Mediação pedagógica e o uso da tecnologia. In: Moran, J. M., Masetto, M.T. \& Behrens, M. A. Novas tecnologias e mediação pedagógica. 19a ed. Campinas, SP: Papirus.pp.133-173.

Morim, E. (2006). A escola mata a curiosidade. Nova Escola. Recuperado de https://novaescola.org.br/conteudo/894/edgar-morin-a-escola-mata-a-curiosidade

Morim, E. (2016).Os princípios do conhecimento pertinente. in Os sete saberes necessário à educação do futuro. São Paulo: Cortez.

Paviani, J. (2014). Interdisciplinaridade conceitos e distinções.Caxias do Sul, RS: Educs.

Perrenoud, P. (2002). A prática reflexiva no ofício de professor: profissionalização e razão pedagógica. Porto Alegre: Artes Médicas.

Sampieri, R. H. Collado, C. H. \& Lucio, P. B. (2006). Metodologia de Pesquisa. Tradução: Murad, F. C., Kassner, M.\&Ladeira, S. C. D. $3^{a}$ ed.São Paulo: McGrawHill. p.583.

Sampiere, H., Callado, C. \&Lucio, M. (2013). Metodologia de Pesquisa. Tradução: Daisy Vaz de Moraes; revisão técnica: Ana Gracinda Queluz Garcia, Dirceu da Silva, Marcos Júlio. $5^{\text {a }}$ ed. Porto Alegre. Penso.

Santos, V. P. (2007). Interdisciplinaridade na sala de aula. São Paulo: Loyola.

Shön, D. (2000). Educando o profissional reflexivo: um novo design para o ensino e aprendizagem. Trad. Roberto Cataldo Costa. Porto Alegre: Artes Médicas Sul. 


\section{APÊNDICE A}

\section{Questionário}

Questionário para os (as) professores (as) do Ensino Médio do Colégio Estadual Dep. Jayro Sento-Sé, BA/ Brasil.

Caro (a) professor (a):

Este questionário visa à obtenção de informações para identificar as concepções e habilidades dos (as) professores (as) do Ensino Médio em relação ao desenvolvimento da prática interdisciplinar.

A consolidação dos dados será objeto de análise em uma tese para o curso de Mestrado em Ciências da Educação na Universidade Autônoma de Assunção/Paraguai.

Queira respondê-lo, por gentileza. Asseguramos o sigilo de sua identificação e agradecemos sua colaboração.

Helisandra dos Reis Santos

I - Histórico Profissional

Sexo

( ) Feminino ( ) Masculino

Ano de ingresso na rede pública estadual

Carga horária semanal

Em quantas escolas trabalha

Vínculo empregatício

( ) efetivo

( ) Contratado

( ) estagiário

II - Formação acadêmica

( ) especialização

( ) Licenciatura

( ) Não possuo

( ) Cursando

( ) mestrado 


\section{Sobre as concepções de interdisciplinaridade}

1 - Interdisciplinaridade é uma prática docente comum na qual, diferentes disciplinas mobilizam-se em uma temática.
Sim
( )
Não sei
( )
Às vezes
( )
Não
( )

2- A interdisciplinaridade pode ser considerada como uma proposta de metodologia de ensino.
Sim
( )
Não sei
( )
Às vezes
( )
Não
( )

3 - Interdisciplinaridade é uma ação em parceria através da interação entre os professores.
Sim
( )
Às vezes
( )
Não sei
( )
Não
( )

4-Interdisciplinaridade é uma atitude de diálogo em compartilhar ideias e experiências na busca de novos saberes.
Sim
( )
Não sei
( )
Às vezes
( )
Não
( )

5- A interdisciplinaridade está relacionada a contextualização do conhecimento.

$\begin{array}{llll}\text { Sim } & (\text { ) } & \text { Não sei } & (\text { ) } \\ \text { Às vezes } & (\text { ) } & \text { Não } & (\text { ) }\end{array}$

Sobre prática interdisciplinar do professor em sua metodologia de ensino

6 - Os conteúdos de sua disciplina estão relacionados com conteúdos de outras disciplinas?
Sim
Não sei
( )
Às vezes
( )
Não
( )

7 - Na sua prática docente há parceria ou interação com os docentes das diversas disciplinas?

$\begin{array}{llll}\text { Sim } & (\text { ) } & \text { Não sei } & (\text { ) } \\ \text { Às vezes } & (\text { ) } & \text { Não } & (\text { ) }\end{array}$

8 - Existem momentos de encontro com os alunos e professores de outras disciplinas? 


$\begin{array}{llll}\text { Sim } & \text { ( ) } & \text { Não sei } & (\text { ) } \\ \text { Às vezes } & (\text { ) } & \text { Não } & (\text { ) }\end{array}$

9 - Durante a explicação de conteúdos há a relação entre a teoria do livro didático e a realidade global, regional e local?
Sim
Não sei
( )
Às vezes
( )
Não
( )

10 - A sua formação na graduação contribuiu para o desenvolvimento da prática interdisciplinar?
Sim
( )
Não sei
( )
Às vezes
( )
Não
( )

Sobre a integração dos docentes no processo do planejamento escolar;

11 - O planejamento é realizado com o coletivo?
Sim
Não sei
( )
Às vezes
( )
Não
( )

12 - No momento do planejamento existe diálogo entre os docentes para compartilhar suas experiências em sala de aula?
Sim
Não sei
( )
Às vezes
Não
( )

13 -Existe diálogo e reflexão entre os docentes para a organização das atividades integradas?
Sim
( )
Não sei
( )
Às vezes
( )
Não
( )

14 - Na organização do Plano de curso das disciplinas, existe uma preocupação em relacionar os conteúdos afins entre as disciplinas?

$\begin{array}{llll} & & \text { Não sei } & (\text { ) } \\ \text { Sim } & (\text { ) } & \text { Não } & (~\end{array}$

\section{Sobre ações interdisciplinares na prática de ensino dos professores}

15 - Na sua prática docente existe participação em projetos escolares que envolva várias disciplinas?
$\operatorname{Sim}$
( )
Não sei
( )
Às vezes
( )
Não 
16 - São trabalhadas atividades extraclasses, que abordam pesquisas com problemas vivenciados pela comunidade escolar?

$\begin{array}{llll}\text { Sim } & (\text { ) } & \text { Não sei } & (\text { ) } \\ \text { Às vezes } & (\text { ) } & \text { Não } & (\text { ) }\end{array}$

17 - Há abordagem de temas transversais mediante os conteúdos trabalhos?

$\begin{array}{llll}\text { Sim } & (\text { ) } & \text { Não sei } & (\text { ) } \\ \text { Às vezes } & (\text { ) } & \text { Não } & (\text { ) }\end{array}$

$18-\mathrm{O}$ relacionamento interpessoal entre os professores é:

$\begin{array}{llll}\text { Ruim } & (\text { ) } & \text { Bom } & \text { ( ) } \\ \text { Regular } & (\text { ) } & \text { Ótimo } & \text { ( ) }\end{array}$

Sobre a abordagem interdisciplinaridade no projeto político pedagógico da escola

19 - A interdisciplinaridade é abordada como eixo integrador das atividades pelo PPP da escola.
Sim
( )
Não
( )
Às vezes
( )
Não sei
( )

20- Os objetivos do PPP fazem referência a práticas interdisciplinares?
Sim
( )
Não sei
( )
Às vezes
( )
Não
( )

21- O PPP menciona projetos a serem desenvolvidos pela escola que envolvam várias disciplinas?

$\begin{array}{ll}\text { Sim } & (\text { ) } \\ \text { Às vezes } & (\text { ) } \\ \text { Não sei } & (\text { ) } \\ \text { Não } & (\text { ) }\end{array}$




\section{APENDICE B}

\section{Roteiro de Observação participante}

Objetivo da pesquisa: Registrar os comportamentos e atitudes dos professores durante o processo de planejamento

\section{Aspectos a serem observados}

1. Como o processo de planejamento é organizado.

1.1 Qual a frequência da realização dos planejamentos:

( ) semanal ( ) mensal ( ) bimestral ( ) anual

Outro

1.2 Como esse planejamento acontece?

( ) Com o coletivo ( ) por área do conhecimento

Outros

2. Durante a realização do planejamento é possível observar interação entre os professores.

2.1 Eles dialogam entre se trocando experiências?

( ) Todos estavam empenhados na realização do planejamento

( ) A maioria estavam empenhados com alguns casos de indiferença

( ) A minoria estavam empenhados enquanto a maioria estavam indiferentes

3. No planejamento entre os professores observou-se a elaboração de atividades envolvendo duas ou mais disciplinas?

( ) sim ( ) não

3.1 Quais são as disciplinas que se envolvem na elaboração de atividades em comum?

4. Durante o planejamento os professores se preocupam na abordagem de temas transversais vivenciados pela comunidade escolar?

5. Outros comportamentos e atitudes observados durante todo processo da coleta de dados 
